"A cyst."

"What cysts occur in the mesentery ?"

Silence.

The candidate thought he had been led into a trap and fell back on the last line of defence-silence.

Another form of tentative advance is to counter with another question, such as "It could not be the gall-bladder?" with a note of interrogation in the voice. This is one of the worst forms of opening; it calls for the inevitable "Why not?" which makes dignified retreat rather difficult.

A third and very common failing of examinees is to unearth the most unlikely explanation for a simple affair and put it first. There were candidates who started with the suggestion that the tumour might be a Meckel's diverticulum.

In such a question as that concerning further aids to diagnosis, simple methods often receive small consideration. It was very properly said by many candidates that a pyelogram should be done, but they did not suggest that the urine should be tested first, or that simple antero-posterior and lateral X-rays of the abdomen should be taken or that some help might first be obtained from a pelvic examination. One candidate gave as his first suggestion that the abdomen should be opened.

If there is any lesson to be drawn from these answers it is that candidates should try to attribute a little more human feeling to examiners, should approach any case with the confidence that they can at least say something about it, and that their opinions and suggestions are worth hearing. They should approach cases in their own ways, speak about them in their own words and not confuse their minds by trying to guess what the examiner is thinking of-fearful of the traps into which they may fall.

The actual nature of such a tumour is a small consideration for the purposes of examination. The student who hits the bull's eye with a shrewd guess is likely to score less marks than the one who reasons well but arrives at a different conclusion.

In the above case there was plenty of scope for discussion. The positive items of evidence were the antero-posterior X-ray film which showed a discrete, calcified mass, the lateral film which showed that this mass was well in front of the spine, and the cholecystography which showed a normal gall bladder above the tumour. This taken with all the negative evidence made an almost certain diagnosis of calcified glands in the mesentery.

\title{
A CASE OF ACUTE COMBINED DEGENERATION OF THE SPINAL CORD OCCURRING IN A PATIENT WITH ADDISONIAN AN EMIA WHO WAS BEING TREATED WITH LIVER EXTRACT.
}

\author{
BY REDVERS IRONSIDE, M.B., M.R.C.P. \\ Assistant Physician, West London Hospital, and Hospital SS. John and Elizabeth.
}

ERNEST B., aged 59, attended hospital three years ago with feelings of lassitude and occasional swelling of the left ankle. Sixteen months ago he noticed failure of appetite and occasional soreness of the tongue.

On examination the heart was slightly dilated. There was no enlargement of the liver or spleen. A blood-count showed-red blood-corpuscles 2,000,000: 
hæmoglobin 40 per cent.; colour index I ; white blood-corpuscles 8,000; with

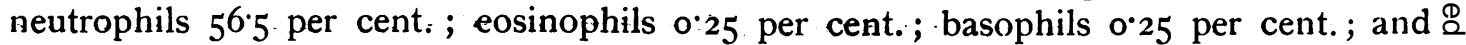

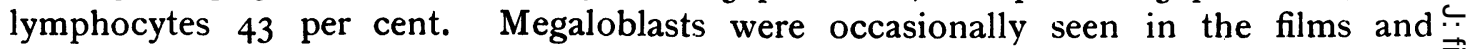
other features of the blood-count were in keeping with the diagnosis of Addisonian $\stackrel{\vec{q}}{\mathrm{f}}$ anæmia. A barium meal of the stomach was normal. A test meal showed achlorhydria. The patient was put on liveroid and hydrochloric acid. Three months later a bloodcount showed 5,600,000 reds; hæmoglobin 92 per cent.; colour index $0 \cdot 8$; white cells 6,200 . The Wassermann reaction was negative in the blood.

Six weeks ago patient began to feel pins-and-needles in the tips of the fingers only. One week ago his legs became stiff and he had difficulty in starting micturition. On examination the optic discs, pupils, cranial nerves and upper limbs were normal. $\vec{\omega}$ Both lower limbs were moderately spastic, and there was weakness at all joints, $\overline{0}$ particularly in the dorsiflexion of both feet. The gait was spastic and ataxic, the $\underset{3}{3}$. patient walking on a wide base. To cotton-wool and pin prick there was slight ${ }_{\infty}^{\infty}$ sensory loss of global distribution over the feet and ankles. Deep muscular sensibility $\stackrel{N}{N}^{-}$ was increased in the calves ; sense of position and passive movement absent in the toes; $\stackrel{\infty}{v}$ and vibration lost over the tibial malleoli, tibiæ and anterior superior iliac spines. $\stackrel{\rho}{-}$ The knee-jerks and ankle-jerks were brisk, the plantars strongly extensor. A blood- $\overrightarrow{7}$ count now showed red blood-corpuscles 3,000,000; hæmoglobin 60 per cent.; colour index I ; white blood-corpuscles ro,00o; with neutrophils 74 per cent.; eosinophils $\stackrel{\text { क् }}{工}$ I per cent. ; basophils I per cent.; monocytes I per cent.; lymphocytes 23 per cent, $\overrightarrow{0}$ There was slight polychromasia and nucleated red blood-corpuscles occasionalif occurred.

In examining the patient the technique of sensory testing was badly performet by most of the candidates. Only a few seemed to have any idea of what was meant by deep muscular sensibility and how this is tested. Many of the candidates omitted to ask the patient to walk. Examination of the gait should never be omitted in any $\overrightarrow{\vec{P}}$ case presenting neurological features. Most of the candidates made the correct $\frac{}{3}$ diagnosis, but very few were able to point out the important and instructive features in this patient's story. These were :-

(I) The patient developed signs of cord disease in spite of treatment with liver extract and hydrochloric acid.

(2) While at first liver seemed to control his anæmia, the last blood-count revealed that then it was not doing so.

(3) The onset of symptoms of combined degeneration of the spinal cord was unusually acute.

While most of the cases of combined degeneration of the cord run a subacute or chronic course over a period of eighteen months to two years or longer and have a slow $N$ onset, the onset in this case was. acute and the symptoms rapidly progressive. Death $N$ in such cases usually occurs from heart failure, due to degenerative changes in the cardiac muscle or toxæmia.

It may interest the candidates to know that during the week after his case wasc shown the patient became rapidly worse and died eight days later. 